\title{
Science, Religion, and Health: The Interface of Psychology and Theology
}

\author{
J. Harold Ellens \\ University of Michigan, Ann Arbor, USA \\ Email: jharoldellens@juno.com
}

How to cite this paper: Ellens, J.H. (2017) Science, Religion, and Health: The Interface of Psychology and Theology. Open Journal of Social Sciences, 5, 25-36.

https://doi.org/10.4236/jss.2017.56004

Received: May 1, 2017

Accepted: June 6, 2017

Published: June 9, 2017

\begin{abstract}
The biblical story, as a paradigm of the human psychological and spiritual odyssey, asserts an inherent union of our experience of history and God's. In the picture that the Bible paints, this is God's world and we live in it. The import of that centers in the reality that life for God, as Spirit, and the life of the human psyche interact, interface, or cut across each other at such a substantive or foundational level as to affect the description and definition of both our psyches and God as Spirit. To employ a meaningful and authentic theology (concept of God) requires a useful and honest anthropology (concept of humankind). To engage anthropology thoroughly and exhaustively lands one finally in theology. One must come at each with an eye to the other. The same can be said as well about the science of any other facet of the cosmos, when viewed as God's created world.
\end{abstract}

\section{Keywords}

Science, Religion, Health, Psychology, Theology, Spirituality, Personality Theory, Anthropology

\section{Introduction}

Religion is barren without a comprehensive appreciation of the creation, and creation at the center can only be comprehensively understood religiously. The natural and social sciences must inquire finally of theology. Theology must listen and speak to the natural and social sciences. Psychology is an applied social science with a base in the natural sciences, just as medicine, education, and preaching are. Psychology properly exercises the stewardship of its mandate by collecting data, formulating theories that account for the data, and applying the interpreted data to concerns in psychotherapy. 
Theory development is, therefore, a religious act. It hinges upon one's point of view and one's outlook on life, namely, it is an act with a faith assumption behind it. That is equally true whether its formulation is secular or sacred. Theory development is one of the key intersections of the natural and social sciences with theology, in that it involves both the assessment of the natural or social science and the application of a world-view assumption to it. That intersection shapes and constrains everything in the natural and social sciences.

\section{Exposition}

This article addresses some of the implications of a thoroughgoing grace theology for psychology theory development. A grace theology is the world view which assumes that God loves all of his creation, and forgives everyone, for everything, for evermore. This paper emphasizes the problem of the intersection of theology and psychology, and the import of a Christian anthropology for responsible development of personality theory.

\section{The Intersection of Theology and Psychology}

Egbert Schuurman was a professor of Christian philosophy at Eindhoven Institute of Technology and lecturer in the philosophy of culture at the Vrije Universität te Amsterdam. He wrote a book some years ago that might be considered a model for handling the issue of relationship between the claims of a Christian confessional worldview and the scientific enterprise. The book is entitled Technology and the Future: A Philosophical Challenge (2009) [1]. Schuurman does not follow the pattern of those Christians who reject technology, or of those who look toward technology as the avenue of salvation for our culture. In his important volume he advocates for an integration of Christian belief and philosophical or scientific thought.

In a true integration like that, a fresh light is allowed to fall on the problems that the positivist empiricists and the post-modernists raise, and upon the mutually contradictory solutions they propose. The latter group is oriented toward human freedom, the former toward technological power. Freedom and power exist for them in an eternally unbridgeable dichotomy, so they must be harmonized in this fresh light.

Professional scientists concerned with the intersection of theology and psychology must, of course, follow a similar course in their present quest. After a profound analysis of both extremes of freedom and power, Schuurman develops the basis for the distinctive contributions the natural and social sciences-and technology-can make. In his previous book, Reflections of the Technological Society (1980), he presents interplay between modern philosophy and modern technology. Christian psychologists must do the counterpart of that in the disciplines of modern theology and modern psychology [2].

Stanley L. Jaki, a distinguished Benedictine priest with doctorates in both systematic theology and physics, has taken a similar approach, in a close look at the 
relationship between psychology and theology. His The Road of Science and the Ways to God (1978) demonstrates from the history of science what a key role rational theology has had in the rise of science and its plethora of applied achievements [3]. He confirms Francis Bacon's choice remark upon the obverse of the argument, namely, that a little philosophy (science) leads one to atheism, but profound philosophy (comprehensive and exhaustive) leads one to theism.

In Cosmos and Creator (1980), the Gifford Lectures, Jaki explored the connection between the anthropology that functions in the natural and social sciences, handled from both a secular and a Christian perspective [4]. Jaki promises to illumine our quest to understand the interface of the psychological and theological sciences. His thrust, like Schuurman's, assumes the essential legitimacy of the secular scientific quest for truth, expects productivity from what the natural and social sciences can offer, and is optimistic about what the theological sciences may produce. He honors what each brings to their intersection and dialogue with each other. He considers that the crucial element in this dialogue is the quality of the perspective each offers the other.

Except for the lunatic fringe of ulra-fundamentalists, there has been a constant and consistent urgency among Christians to avoid forcing a perceived dichotomy between faith and science, or forcing a contrived unity between the two. God does not speak with a forked tongue, so we must assume that what we learn in nature about God's story for us, and what we learn in scripture about God's story for us, are a unified revelation. God speaks in nature and in grace, in God's created world and in the world of the word of the Bible. The Christian professional is called to embody a sound theology and a sound psychology on the assumption that thus both will come out with sophisticated application and scientific integrity.

Our perspectival model of the interface of psychology and theology inspired us to look for the way each scientific enterprise, theology and psychology, may profit from the light that each can bring to the other's science. Each of these scientific endeavors may be approached from the perspective of the other and, hence, each may be formed and informed by the other. If both are thoroughly pursued there can be no tension between them in the long run. Each tells the story of the human person in its own way. Telling that same story from two different directions with two different symbol systems is not the same as saying two different things. What the Bible and science say, touching history and the cosmos do not stand in an inherent inconsistency. It seems to me that there are four areas in which the sciences of psychology and theology interact: in the work of Theory Development Level, in the design of Research Methodology, in the mode of collection of the Data Base, and in the Clinical Application. These are the places of intersection at which constructive work can be done in relating the science of psychology to the science of theology. At these junctures or nodes each must illumine the other or both are deprived of a comprehensive robust and honest science. 


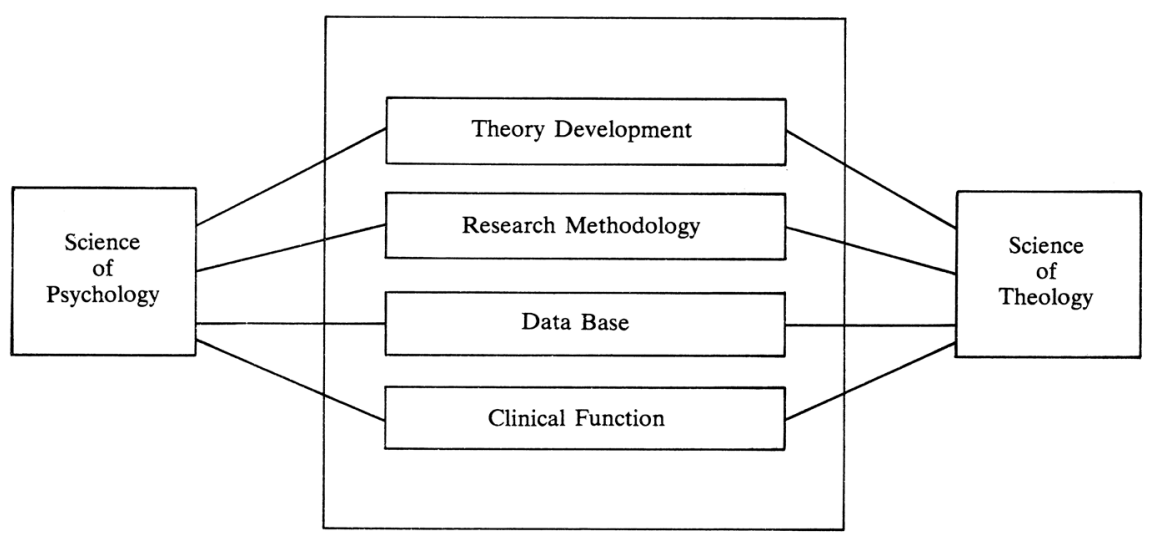

Moreover, these four levels of scientific inquiry always remain interactive, mutually forming and informing the shape and perspective of each of the other levels. Then we can be integrated persons, who are sophisticated Christian theologians and sophisticated psychologists.

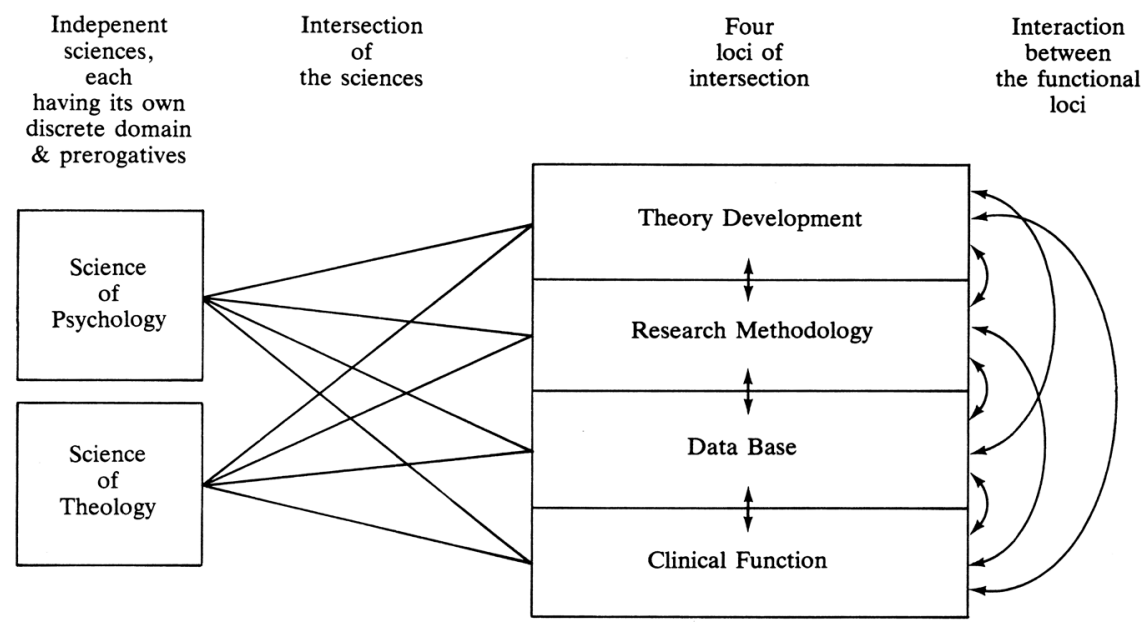

It may be urged that instead of thinking of a tension, let us assume an integral and inherent harmony between our scientific theology and our psychology, between our scientific view of persons and our experiences of them. Human nature is a unity, centered in a creature who is psychical and physical, but yet spiritual at the core. We need not construct a unity between psychology and theology but merely to discover the integral unity there, allowing the phenomena to reveal to us its authentic integrity.

We have noted that theology and psychology intersect at the levels of theoretical assumptions, research methodology, data base management, and clinical application. They are busy forming and informing one another at each level. The subject of study at each level is the human person. It is apparent, therefore, that the phenomenon in which the intersections of theology and psychology are discerned and realized is the anthropological model that functions or is forming at each of the four levels of intersection.

One might say that an engine runs on gasoline in gaseous form and on oxygen 
and hydrogen molecules in gaseous form. One might further explain that the engine works because in it these two gaseous elements, gasoline and air, intersect, forming and informing each other. For an especially interested student, one might go on to explain that the intersection is evident at various levels, at the level of the carburetor and at the level of combustion chamber in the cylinder. With an even more precocious student one might continue and suggest that the specific component in which the intersecting gas and air interact is the Venturi tube in the carburetor. In autos these days, of course, you would need to mention the fuel injectors instead of carburetors.

I see something like that as the role of the anthropological component in each of the loci of intersection of theology and psychology. That concept of the nature of humanness is functioning or forming there that each of the sciences brings to the intersection, and both are mutually illumining and shaping the intersection. The integrality of the whole is realized then, in terms of the anthropological authenticity we experience regarding the impact of psychology and theology in our assumptions and theory development; our research methodology and hypotheses; our data collection sources, methods, and designs; and our clinical function and fruitfulness. The authenticity of that process will manifest itself in the theoretical formulation and in the empirical experience of the outcome.

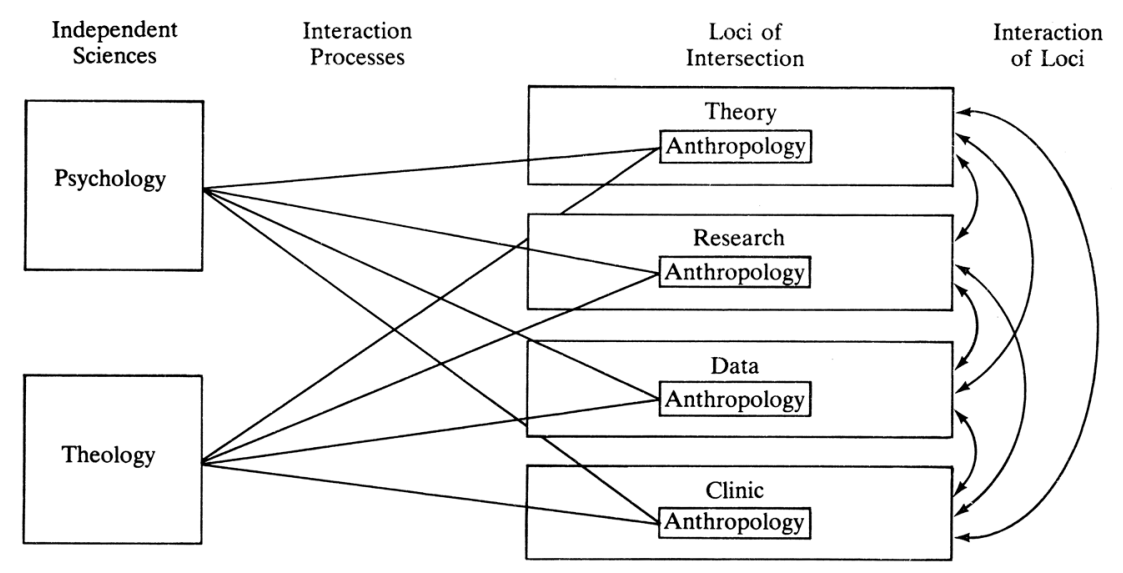

The anthropological concept that is forming or funtioning in each locus of intersection is the actual junction element that constitutes the cite of intersection.

So, sound pursuit of the inevitably religious enterprise of psychology theory development, informed by our best insights from speculation, research, empirical evidence, and clinical experience, will inevitably be a conscious and creative quest for a warrantable anthropology. If we can thus achieve a warrantable concept of the nature of humans, we will be able to formulate an authentic personality theory, theories of pathology, and theories of healing, wholeness, and wholesomeness.

The key problem for developing a warrantable anthropology within the ferment of the intersection of theology and psychology is one of establishing the criteria for judging truth as truth, and apparent truth as falsehood. This book is 
not going to solve that problem but, rather, focus it and hold out for two critical elements in that solution. Further study will be necessary at precisely this locus if the dialogue regarding science and the theology is to move ahead. We, as the community of religious psychologists, have danced all around this issue but have not resolved the impasse. We must do that or our digestion of the relationship of theology and psychology will again be as constipated and fruitless as it was three or four decades ago.

Let us push the matter forward with the following observations. First, the scientific method, classically formulated by Aristotle, Aquinas, and Francis Bacon, is indispensable to our investigation of both the psychological and theological sciences if we are to obey the first principle of Christian scientific theory development, namely, that our theories must be warrantable and certifiable theories. Warrantable means that they are as thoroughly in conformity to the whole truth at our disposal as we have the resources to make it possible.

The second critical element in the solution of the problem of norms and criteria for judging truth is awareness that truth to the Greeks (alytheia) was one thing, and to the Hebrew Bible tradition ('emeth) it was quite another. The modern world of science and technology has been uniformly dominated by the Greek notion of truth, with its implied rational empiricism. Post modernism has called that notion into question with very good reason. As scientists now acknowledge, there is a wide world of truth to be known outside the boundaries of what can be accessible through rational empirical means. This is a mindset or realization that seems to long for the Hebrew model of truth.

Torlief Boman (1960), in Hebrew Thought Compared with Greek argued that for the Greeks, truth was that which is evident, clear, and seen [5]. For the Hebrew Bible, truth is that which is dependable, faithful, and trustworthy. The Greek notion deals with objectivity, the Hebrew with subjectivity. Hebrew truth is not metaphysical, but characterological, phenomenological, heuristic, and covenantal or interpersonal. It is, for example, a matter of trust between persons, including God and humans.

\section{Truth: Hebrew and Greek}

It is not surprising that in the worldview of the biblical theologian, as long ago as the earliest pages of the Bible, the idea that God had covenanted with humanity to guarantee certain basic truths, such as God's universal forgiving grace: forgiveness for everybody, for everything, for evermore (Genesis 12 and 17). This upholds the human status of God's compatriot, a status never to be abrogated under any circumstance. Neither is it surprising that the Hebrew tradition was not recorded in philosophical treatises like those of the classical Greek humanists. It was preserved instead, in the very personal record of human experience of, and perceptions about, the mighty acts of God in human history. For the Greeks, truth was evidential and hence static through time, inherent in creation, as are mathematical facts. For the Hebrews truth was dynamic, unfolding through time, implied in creation but realized in the perpetual process of the re- 
demptive and providential process of re-creation, unveiling, and revelation in human experience.

Greek truth required one to stand outside the system and observe the evidence and logic of it. Hebrew truth required one to stand inside the system to feel and hear the confirmation of the dynamic process of truth exuding from experience, unveiling, a process of discovery. Even the word of the prophets and of the man from Nazareth, the incarnate Logos, was ultimately useful to the degree that it became a personal encounter with a truth from God.

To establish adequate criteria for assessing the data of experience, or of rational reflection, or of logical deduction, as truth, it is imperative that we devise sound strategy and tactics for applying the constraints of the scientific method to the Hebrew type of truth. Abraham Maslow's insistence upon the truth-value of the world of feelings and emotions (1992) has radically revised our culture's perception of truth and moved us solidly into the Post-Modern way of thinking [6]. This orientation has been greatly advanced by the work of Positive Psychology, especially that of Marty Seligman (Flourish, 2011 [7], Authentic Happiness, $2002[8])$.

This Post-Modern way of thinking argues that all truth is not "out there" and objective; to be seen best from the outside in, observed from the point of view of a spectator. Post-Modernism has compelled us to deal with the reality that there is a vast world of phenomenological truth which is relatively subjective and is best appreciated from the inside out, that is, from within the experience as it is happening. Client-centered therapy is built largely upon this hypothesis, devolving from a specific anthropological view that very much crucial truth, especially that, which is relevant in the clinical setting, is psychological and personal in the Hebraic sense.

It is clearly the case that both of these perspectives on truth are correct regarding those arenas of truth to which each applies. They are scientifically useful when held together. It is intriguing to notice that Aristotle, the father of the scientific method, in his move away from Platonic speculative idealism to rational empiricism, was aware of this crucial insight. He preferred to think of himself, not as a philosopher in the Pythagorean tradition, but as a psychologist. However, he never worked out this issue or moved beyond the classical view of truth. It is likely that if Western ecclesiastical development had followed Aurelius Augustine, however, as the Eastern Church did, instead of Anselm and Aquinas and the unresolved problem of Aristotelianism, the modern era would have been shaped by a Hebrew notion of truth and method, rather than Greek. That posture of truth as subjective and covenantal, rather than objective and empirical, is still evident in the Eastern Church's preference for theology as celebration. This is a psychological phenomenon, versus the Western Church's preference for theology that is propositional and nomistic, an essentially logic phenomenon [1].

The force of contemporary psychology and the oriental notions of truth impinging upon the West from Eastern Religions are moving American culture 
toward a balance between Greek and Hebrew perceptions of truth. That will make us more able to employ sound anthropology and help resolve the quest for the Christian interface of theology and psychology.

\section{Psychological Anthropology}

While theological anthropology tends to follow either a biblical theological concept of the nature of human beings or the philosophical theological perspective of Paul Tillich, psychological anthropology takes the form of a variety of personality theories. One of the most helpful is that of Salvadore R. Maddi (1996) [9]. Maddi's study treats the classic theorists from Freud to Seligman in terms of two primary categories: the manner in which each theory illumines matters regarding the core of human personality and the way each treats the periphery of human personality. Within these two categories he describes each theory in terms of its essence as a conflict model or a fulfillment model of personality. $\mathrm{He}$ presents his own model, which he calls the consistency model, and then critiques each in terms of rational empirical criteria, applicable to both of the primary categories of core and periphery. Maddi defines personality as a stable set of characteristics and tendencies that determine those commonalities and differences in the psychological behavior (thoughts, feelings, and actions) of people that have continuity in time and that may not be easily understood as the sole result of social and biological pressures of the moment. Tendencies are the processes that determine directionality of thought, feelings, and actions. They are in the service of goals or functions. Characteristics are static or structural entities, usually implied by tendencies, which are used to explain not the movement toward goals or the achievement of function but rather the fact and content of goals or requirements (Maddi, 10).

So human personality is a concept used to describe the observed phenomena that indicate the kind of person a given individual is, as indicated by his or her type of response to life situations. The interpretation, of course, implies a perspective determined by one's essential assumptions regarding the nature of humanness. The anthropology operating is that concept of human nature that is functioning or forming in the interplay of those essential assumptions and the observed phenomena (data).

Core attributes of personality are those features that disclose the inherent attributes of humans. Periphery facets of personality, according to Maddi, are learned and not inherent. They are concrete and close to the behavior itself, which is observed. Concerning the conflict, fulfillment, and consistency models, Maddi makes the follow points.

The conflict model assumes that personality is the product of two great opposing and unchangeable forces, functioning at the psychosocial or the intra-psychic level, between which forces the person is achieving a dynamic balance, or a denial of either or both. The fulfillment model assumes only one force, localized in the person, and moving toward either actualization or perfection. The consistency model assumes no great dynamic forces at all, but rather a dy- 
namic growth process of interaction with and feedback from the environment. "(I)f the feedback is consistent with what is expected, or with what has been customary, there is quiescence. But if there is inconsistency between the feedback and the expectation or custom, there is pressure to decrease this uncomfortable state of affairs. Life is understood as the extended attempt to maintain consistence" (Maddi, 24).

Maddi cites Freud [10] and Murray [11] as representing the conflict model, psychosocial version; Rank, Jung [12], Perls, and others as examples of the conflict model, intra-psychic version. Rogers [13], Maslow, and Seligman illustrate the fulfillment model actualization version; Adler, White [14], Allport, Fromm [15], and Ellis, the fulfillment model, perfection version. The consistency model, cognitive dissonance version, includes the work of Kelly, McClelland, and Festinger; the consistency model, activation version, that of Fiske and Maddi. It is precisely within the personality theory prevailing in each anthropological concept that is forming or functioning within each locus that the sciences of psychology and theology intersect. The critical issue here is the need to ferret out the anthropological assumptions and consequences of each of these personality theories and to determine how, in the interplay between the assumptions and the data, the psycho-theological anthropology is being shaped. This is crucial for determining how one may responsibly bring a grace theology-formulated as the principles and perspectives of a tentative biblical anthropology-to bear on the interpretation of the observed behavioral data. Does it foster a soundly mature theological and psychological anthropology and personality theory?

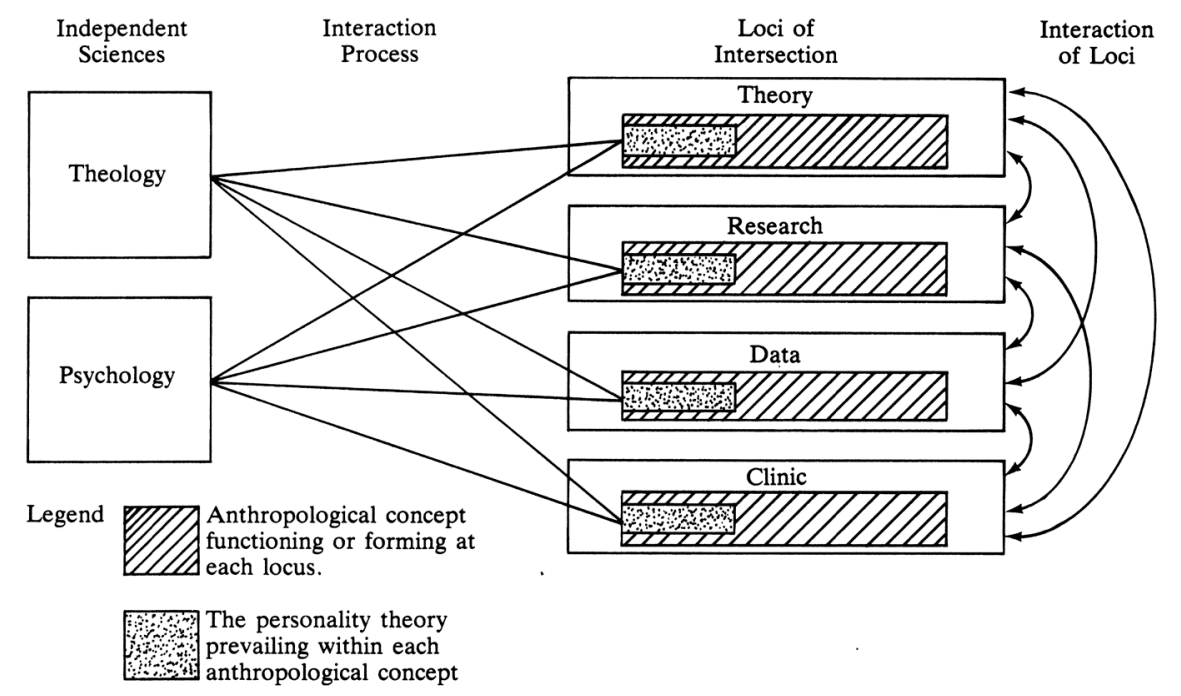

\section{Conclusions}

What must be asserted first, in drawing conclusions from all this, is that neither the biblical assumptions nor the empirical or psychological data has a higher warrant as truth or a higher logical, psychological, or theological valence than the other. Both must vitally participate in the interface of assumptions and data, for a mature anthropology and personality theory to evolve. 
Secondly, it is the contention of this article that the assumptions of the Godcompatriot model of human status and the God-imager model of human nature, cast in terms of the evident brokenness of humans, are a crucial part of the assessment that must be fed into the personality theory model. Moreover, this entire set of phenomena must be formulated in terms of the reality of the radical, unconditional and uncalculating, and universal nature of God's forgiving grace. This is an absolutely crucial assumption to bring to bear upon the data, with a view to achieving an authentic psycho-theological theory-development process. Not only is this true in the area of personality theory- development, but in all other areas of psychology theory-development as well.

Third, a sound theory must be operational, in the sense that it provides adequate tools for the handling of concept-definition and the associated concept-measurement necessary to manage authentically the full range of data. A sound theory also must be precise, in that it must deal with the data pertinent to the specified problem or concern. Furthermore, it must be empirically, philosophically, and psychologically valid, in the sense that it manages the full range of data from all sources: empirical data, philosophical-theological assumptions, and psychological perceptions.

Fourth, psycho-theology theory development is crucial at each level of the intersection of psychology and theology: conceptual theory, research methodology, data base management, and clinical experience.

Fifth, there is a wide variety of personality theories, as Maddi sees them, or as in the Hall-Lindsey (1978) categories: psychoanalytic, psychological, personological, field theory, individual, oranismic, factor theory, S-R, operant-eincent, self-psychology, existential, and behaviorist [16]. They all really come down to four types: rational, emotional, relational, and biological theories. For example, one might place Ellis in the First, Maslow and Rogers in the second, Perls and Erhard in the third and Skinner in the fourth.

If one assumes humans to be essentially rational, that affects one's theory of education and healing (therapy), because it affects one's psycho-theology of immaturity and illness. It suggests that illness is a deficit of appropriate information or coherence, as is immaturity. Education and healing require information and insight. If one assumes humans to be essentially emotional in nature, education and healing require sensitivity and freedom; immaturity and illness are from blocked emotionality. Relationality as a model of how persons are, assumes the need for confrontation and interaction as states in which persons realize their actualized personhood. The biological definition of human nature assumes that illness or immaturity is the result of inappropriate stimuli, producing a pathological state of response. So both healing and education require the introduction of a proper $S-R$ process.

When one applies such categories as these to our work, the crucial role one's anthropology plays in one's psychology theory development is readily evident. One can see how real the essentially religious nature of scientific theory development is. How crucial a difference is made in sound psychology theory-eve- 
pment by the enrollment of a biblical anthropology into the interaction of theological assumptions and data and psychological assumptions and data!

Sixth, at the very least, sound biblical anthropology will disclose the fact that each of the four types of personality theory indicated above contains theologically valid elements: rational, emotional, relational, and biological. A full-fledged Christian theory requires adequate comprehension of all these elements. Likewise, though a biblical theology seems to me to militate in favor of Maddi's fulfillment model, actualization version, with such representatives as Rogers, Maslow, Seligman, and the Positive Psychologists, it must be said that, were one to adopt Maddi's categories completely, a sound biblical anthropology would disclose crucial truth in each of the models listed.

Seventh, if a sound psycho-theological anthropology is crucial to personality theory development, it will be crucial, as well to the development of a theory of illness, a theory of wholeness, and a theory of healing (therapy).

In sum, I see theology and psychology as different perspectives or frames of reference, with differing terminology, dealing with the same subject matter. Allport emphasized the importance of translating insights and concepts from each science for the other. They interact at four levels in the quest for truth about their subject: at the theoretical level of assumptions and concept and theory definition, at the research methodology level, at the data base level (what data to look for, how, management of the data), and clinical experience level. Their common subject is humanness or the nature of human beings. They intersect, therefore, in the anthropology that is functioning or forming at each level of intersection. The function and formation of anthropology at each level must continually form and inform the anthropology that is forming and functioning at all the other levels. Thus may the total range of potential insight in this quest for the truth about psychology and theology totally form and inform each other. Thus the entire enterprise will operate in terms of an authentic and unified personality theory. That makes possible a psycho-religious enterprise in the helping professions.

\section{Acknowledgements}

This Paper was presented in a substantially different form in J. Harold Ellens (2016), Science, Religion, and Health, Eugene, OR: Wipf \& Stock, 26-39.

\section{References}

[1] Egbert, S. (2009) Technology and the Future: A Philosophical Challenge. Paideia Press, Philadelphia, Reformed Publishing Project.

[2] Egbert, S. (1980) Reflection on the Technological Society. Wedge, Toronto.

[3] Jaki and Stanley L. (1978) The Road of Science and the Ways to God. University of Chicago Press, Chicago.

[4] Jaki and Stanley L. (1980) Cosmos and Creator. University of Michigan, Ann Arbor.

[5] Boman and Thorleif (1960) Hebrew Thought Compared with Greek. Jules L. Moreau, (tr), Norton, New York.

[6] Maslow and Abraham (1992) Motivation and Personality, Harper, New York. 
[7] Seligman and Martin, E.P. (2012) Flourishing-A New Understanding of Happiness and Well-Being. Atria Press, Philadelphia.

[8] Seligman and Martin, E.P. (2002) Authentic Happiness, Using the New Positive Psychology to Realize Your Potential for Lasting Fulfillment. Simon and Schuster, New York. See also Seligman (2006) Learned Optimism: How to Change Your Mind and Your Life. Vintage, New York.

[9] Maddi and Salvatore, Eds. (1996) Personality Theories: A Comparative Analysis. Cole Publishing, New York.

[10] Freud and Sigmund (2013) New Introductory Lectures on Psychoanalysis. Stracey, J., Ed., and Trans., Martino Fine Books, New York.

[11] Murray and Gilbert (2010) Five Stages of Greek Religion. Creative Space. Independent Publishing Platform, New York.

[12] Jung and Carl G. (1958) The Undiscovered Self. Hull, R.F.C., Trans., Little Brown, Boston, Signet.

Jung (1964) Man and His Symbols, Garden City. Doubleday, New York. Jung (1966) Psychology and Religion. Yale University Press, New Haven.

[13] Rogers and Carl (1965) Client Centered Therapy. Houghton Miflin, New York.

[14] White and Robert, W. (1956) Abnormal Personality. Ronald Press, New York.

[15] Fromm and Eric (1970) Psychoanalysis and Religion. Bantam, New York. Fromm and Eric (1910) The Heart of Man, Its Genius for Good and Evil. Lantern Books, New York.

Fromm and Eric (1997) The Anatomy of Human Destructiveness. Pimlico, New York.

[16] Hall, Calvin, S. and Lindzey, G. (1978) Theories of Personality. John Willey and Sons, New York.

Submit or recommend next manuscript to SCIRP and we will provide best service for you:

Accepting pre-submission inquiries through Email, Facebook, LinkedIn, Twitter, etc. A wide selection of journals (inclusive of 9 subjects, more than 200 journals)

Providing 24-hour high-quality service

User-friendly online submission system

Fair and swift peer-review system

Efficient typesetting and proofreading procedure

Display of the result of downloads and visits, as well as the number of cited articles

Maximum dissemination of your research work

Submit your manuscript at: http://papersubmission.scirp.org/

Or contact jss@scirp.org 